\title{
Membongkar Isi Pesan dan Media dengan Content Analysis
}

\author{
Gusti Yasser Arafat \\ UIN Antasari Banjarmasin
}

\begin{abstract}
Content analysis in a quantitative research tradition is a method of communication science research and also for some of another social sciences branch. The quantitative content analysis is in the scope of positivistic paradigm that put its researcher as a neutral scientist who do not take a side and forbidden prohibited to product opinion. The researcher is only need to collect and then categorizing meaning of a content such as text, image, sign, and symbol. Content analysis is also able to test a hipotetic using deductive methode by series of statistic test. In communication sciences, this research methode model would powerful to answer how the media effect which impact to public and analyzing the people all at once. The difference between social construct in society and the recontructed reality by the media would being explained using this great methode. Content analysis is capable to measure the accuracy level of message producer and where it's inclined.

Keywords: content analysis, quantitative, research, communication science, message, media.
\end{abstract}

\section{Pendahuluan}

\section{Pembahasan}

Pengertian Istilah Methode Analisis Isi (Content Analysis)

Menurut beberapa pakar, analisis isi dimaknai sebagai berikut:

- Holsti : 
Analisis ini adalah suatu teknik dalam mengambil kesimpulan dengan mengidentifikasi pelbagai karakteristik khusus suatu pesan secara obyektif dan sistematis. ${ }^{1}$

- Berelson :

Analisis isi adalah teknik penelitian untuk mendeskripsikan secara kuantitatif, obyektif, dan sistematik, dari suatu isi komunikasi. ${ }^{2}$

- Stone :

Analisis isi adalah suatu teknik penelitian untuk membuat perujukan pengenalan karakteristik tertentu di dalam teks secara sistematik dan obyektif. 34

- Krippendorff :

Analisis isi sebagai suatu teknik penelitian untuk membuat inferensi-inferensi yang dapat ditiru (replicable) dan sahih data dengan memperhatikan konteksnya. Sebagai suatu teknik penelitian, analisis isi mencakup prosedur-prosedur khusus untuk pemprosesan data ilmiah. 56

- Cartwrigt :

Analisis isi (dengan menambahkan istilah "coding") menunjukkan deskripsi kuantitatif, sistematik, dan obyektif, dari suatu perilaku simbolik. ${ }^{7}$

\footnotetext{
${ }^{1}$ O. R. Holsti, "Contents Analysis for the Social Sciences and Humanities", melalui Wisnu Marta Adipura, "Analisis Isi", dalam buku Metodologi Riset Komunikasi: Panduan untuk Melakukan Penelitian Komunikasi, Suntingan Pitra Narendra, (Yogyakarta: Balai Kajian dan Pengembangan Informasi Yogyakarta dan Pusat Kajian Media dan Budaya Populer Yogyakarta, 2008), hlm. 104

${ }^{2}$ Pawit M. Yusup, “Analisis Isi”, dalam website http://images.andamawara.multiply.Multiplycontent.com/attachment/0 /SaLkKwoKCDcAAF9z2TI1/analisis\%20isi.pdf?nmid=211490085

${ }^{3}$ Ibid.

${ }^{4}$ Klaus Krippendorff, Content Analysis : Introduction toIts Theory and Methodology, terjemahan Farid Wajidi, (Jakarta: PT. Raja Grafindo Persada, 1993), hlm. 19

${ }^{5}$ Ibid

${ }^{6}$ Wisnu Marta Adipura, "Analisis Isi”, dalam buku Metodologi Riset Komunikasi: Panduan untuk Melakukan Penelitian Komunikasi, Suntingan Pitra Narendra, (Yogyakarta: Balai Kajian dan Pengembangan Informasi Yogyakarta dan Pusat Kajian Media dan Budaya Populer Yogyakarta, 2008), hlm. 102-103

${ }^{7}$ Pawit M. Yusup, loc. cit.
} 
Wisnu menuliskan "analisis isi adalah sebuah alat riset yang digunakan untuk menyimpulkan kata atau konsep yang tampak di dalam teks atau rangkaian teks". ${ }^{8}$ Selain tokoh di atas beberapa tokoh lain juga ada yang mendefinisikan analisis isi dengan beragam antara lain: Charles R. Wright, George V Zito, McQuail, dll.

Lasswell sebagai pelopor analisis isi memperkenalkan teknik pengkodean simbol, yakni mencatat lambang atau pesan yang disusun secara sistematis, lalu kemudian diberi interpretasi. Berdasarkan beberapa pengertian di atas dapat ditarik kesimpulan bahwa analisis isi digunakan oleh peneliti yang ingin memperoleh penjelasan yang terkandung suatu isi komunikasi yang sampaikan dalam bentuk tanda-tanda, simbol-simbol, lambang-lambang atau kriteria-kriteria tertentu lainnya. ${ }^{9}$

Analisis isi merupakan penelitian yang bersifat pembahasan mendalam terhadap isi suatu informasi yang termuat dalam suatu media massa (analisis isi obyeknya terutama adalah media massa). Semua obyek yang diteliti akan dipetakan dalam bentuk tulisan/lambang dan kemudian diberi interpretasi satu-persatu. Akan tetapi pada media yang sifatnya audio tetap harus perlu didengarkan, dengan tetap harus menuliskannya kembali. Begitu pula dengan media-media visual. Tujuannya untuk mengetahui semua karakter penyampaiannya. Analisis isi merupakan suatu teknik penelitian yang berusaha membuat inferensi-inferensi yang dapat ditiru (replicable) dan sahih data dengan memperhatikan konteksnya. ${ }^{10}$ Analisis isi dalam penelitian kuantitatif dipergunakan untuk membongkar

\footnotetext{
${ }^{8}$ Wisnu Marta Adipura, op. cit., hlm. 103

${ }^{9}$ Anonim, “Konsep-Konsep Pokok Analisis Isi Komunikasi”, dalam website http://pustaka.ut.ac.id/puslata/online.php?menu =bmpshort_detail2\&ID=384_modul_metode_penelitian_komunikasi_kode_skom4436

${ }^{10}$ Diposkan Aeconomic, "Pornografi Dalam Komik" (Analisis Isi Pornografi Dalam Komik Jepang Berjudul Ranma 1/2 Dan Love Hina)", dalam website http://one.indoskripsi.com/judul-skripsi/ilmu-komunikasi/\%E2\%80\%9Cpornografi-dalamkomik\%E2\%80\%9D-analisis-isi-pornografi-dalam-komik-jepang-be
} 
muatan teks atau isi kandungan komunikasi yang sifatnya nyata (manifest). Analisis isi akan banyak berkutat pada "what"-nya Lasswel.

\section{Kegunaan Analisis Isi}

Analisis isi dapat digunakan untuk melakukan penelitian yang tidak hanya sebatas pada deskriptif saja tetapi juga bisa digunakan untuk menguji suatu hipotesis. Di beberapa kondisi ada kecenderungan bahwa kajian analisis isi memang ditujukan untuk menguji suatu hipotesis. Meskipun begitu analisis isi dapat juga digunakan untuk kajian-kajian yang sifatnya eksploratif juga deskriptif. Pada dasarnya analisis isi dapat digunakan untuk menganalisa semua bentuk komunikasi, semisal muatan pada pelbagai media cetak (buku majalah, surat kabar, selebaran-selebaran, surat, dll), media elektronik (televisi, radio, internet, dll.), lebih spesifik lagi seperti: puisi, lagu (musik), film, teater, lukisan, peraturan, Undang-undang, makalah, cerita rakyat (legenda, mitos, dongeng, komik, dll), atau bahan yang terdokumentasi lainnya.

Pakar analisis isi Holsti memaparkan terdapat tiga bidang disiplin ilmu yang banyak menggunakan analisis isi ini, hampir $75 \%$ dari keseluruhan studi empirik, yakni penelitian sosio-anthropologis $(27,7 \%)$, penelitian komunikasi umum $(25,9 \%)$, dan ilmu politik $(21,5 \%)$. Tidak terlalu tepat juga kalau mengatakan bahwa semua penelitian sosial dapat memberlakukan analisis ini, Karena beberapa literer menyangsikan pemenuhan prasyaratnya. Analisis isi dapat dipergunakan kalau mempunyai syarat-syarat di bawah ini:

- Data atau obyek yang diteliti sebagian besar merupakan bahanbahan yang terdokumentasi, semisal koran, buku, catatancatatan, dan lain-lain. 
- Terdapat keterangan pelengkap atau kerangka teori tertentu yang menjelaskan mengenai data dan metode pendekatannya.

- Peneliti mempunyai kemampuan teknis untuk mengolah datadata yang dikumpulkannya karena beberapa dokumentasi itu sifatnya sangat khas. ${ }^{11}$

Sehubungan dengan penelitian dalam ilmu komunikasi, analisis isi digunakan pada tiga jenis penelitian komunikasi. Penelitianpenelitian komunikasi itu adalah:

- Penelitian yang bersifat deskriptif.

Biasanya untuk mempermudahnya dilakukan dengan cara membandingkan :

- Pesan dokumen yang sama pada waktu yang berbeda. Analisis dapat membuat kesimpulan tentang kecenderungan isi komunikasi

- Pesan dari sumber yang sama (tunggal) dalam situasi yang berbeda. Untuk mengetahui pengaruh situasi terhadap isi komunikasi.

- Pesan dari sumber yang sama terhadap penerima yang berbeda. Untuk mengetahui pengaruh ciri-ciri audience terhadap isi dan gaya komunikasi

- Pesan dengan pesan, membandingkan isi komunikasi terhadap waktu, situasi atau audience yang berbeda. Untuk mengetahui kontigensi.

- Uji hipotesis tentang perbandingan pesan dari dua sumber berbeda (antarkomunikator)

${ }^{11}$ Niken Restaty, "Riset Periklanan", dalam website http://pksm.mercubuana.ac.id/new/elearning/modul-riset-periklanan-3 sks_niken_restaty/43018-9-792956142617.doc 
- Penelitian tentang penyebab pesan hasil dari pengaruh dua pesan oleh dua sumber pada variable perilaku yang kemudian bisa memunculkan motif, sikap dan nilai pada source B

- Penelitian yang ingin mengetahui suatu efek pesan dari sumber A ke penerima B. ${ }^{12}$

\section{Tujuan Analisis Isi}

Kalau pada penelitian survei dikenal studi dokumen, yakni kajian yang menilik dalam isi suatu data, maka pada analisis isi juga demikian, menggunakan hipotesis formal (hipotesis yang umum lazim digunakan dengan bersandar pada kebenaran terdahulu), kemudian dengan kaidah-kaidah keilmuan lalu dianalisa dengan menggunakan bantuan teknik statistik modern, bisa juga dengan bantuan komputer (teknologi). Jadi ada kesamaan antara tujuan analisis isi dengan penelitian survei (studi dokumen).

Holsti mengemukakan ada tujuh tujuan dalam analisis isi, seperti berikut di bawah ini:

- Menjelaskan kecenderungan isi (esensi) komunikasi

- Menjelaskan karakteristik yang diketahui dari sumber kepada pesan yang dihasilkan

- Memeriksa atau mengaudit isi komunikasi terhadap standar yang berlaku (yang diakui)

- Menganalisa teknik persuasi

- Menganalisa gaya suatu tulisan

- Menghubungkan atribut (sifat dan perlengkapan)

- Menjelaskan pola-pola komunikasi13

\footnotetext{
${ }^{12}$ Saifullah, "Pengaruh Iklan Politik di Televisi Pada Pilpres 2009 Terhadap Perilaku Pemilih di Makassar”, dalam website http://Dunia_komunikasi?/pengaruh-iklan-politik-di-televisi-pada.html

${ }^{13}$ Pawit M. Yusup, loc. cit.
} 
Menurut Wimmer dan Dominick (2000) tujuan dari analisis isi, yakni:

- Menggambarkan isi komunikasi (describing communication content).

- Menguji hipotesis tentang karakteristik pesan (testing hypotheses of message characteristic).

- Membandingkan isi media dengan dunia nyata (comparing media content to the "real world").

- Memperkirakan gambaran media terhadap kelompok tertentu di masyarakat (assessing the image of particular groups in society).

- Mendukung studi efek media massa (establishing a starting point for studies of media effects).

- Tujuan dari analisis isi lebih dititikberatkan pada tujuan menggambarkan isi komunikasi dan mendukung studi efek media massa. ${ }^{14}$

\section{Tugas Pokok dalam Analisis Isi :}

- Menggambarkan sampel dokumen

- Membatasi isi kategori, yakni isi yang bergantung pada tujuan kajian

- Membatasi unit rekam

- Membatasi unit konteks

- Membatasi sistem enumerasi15

\section{Langkah-Langkah Strategis dalam Analisis Isi}

- Menentukan dan menetapkan desain atau model penelitiannya.

\footnotetext{
${ }^{14}$ Di-pos-kan aeconomic, loc. cit.

${ }^{15}$ Andre Yuris , "Communication Science: Content Analysis (Analisis isi)", dalam website http://andreyuris.wordpress.com/2009/09/02/analisis-isi-content-analysis/\#more-320
} 
Yang termaktub di sini adalah menetapkan berapa jumlah media, menentukan korelasi atau perbandingannya, dan menetapkan banyaknya obyek.

- Mencari dan mengumpulkan data primer atau data pokok. Bisa dilakukan dengan menggunkan lembar-lembar formulir pengamatan. Teks adalah obyek pokok dalam analisis isi.

- Menempatkan penelitian pada kondisi yang mempunyai keterkaitan dengan faktor-faktor lain yang juga mungkin berpengaruh. ${ }^{16}$

\section{Tahapan dalam Prosedur Analisis Isi}

1. Merumuskan pertanyaan penelitian (beserta hipotesisnya, jika diperlukan)

2. Memilih mediatau sumber data yang relevan dengan untuk menjawab rumusan masalah

3. Melakukan teknik sampling pada sumber-sumber data yang telah ditentukan

4. Mencari definisi operasional yang mampu menjelaskan teks-teks

5. Membuat kategori yang digunakan dalam analisis

6. Pendataan suatu sampel dokumen yang telah dipilih dan melakukan pengkodean (koding data), kemudian memperjelas isi-isi ringkasan

7. Membuat skala dan item-item sesuai kriteria, frekuensi (penampakan/kemunculan), intensitas untuk pengumpulan data

8. Menafsirkan/menginterpretasi data yang diperoleh berdasarkan teori yang digunakan dan hipotesis pemikiran. ${ }^{17}$

\footnotetext{
${ }^{16}$ Andre Yuris, ibid.

${ }^{17}$ Wisnu Martha Adipura, op. cit., 109-112
} 
Langkah-langkah di atas harus dilaksanakan secara berurutan, tidak boleh terlompati atau menanggalkan salah satu atau lebih nya. Sebab setiap langkah selanjutnya adalah prasyarat untuk ke langkah selanjutnya.

\section{Teknik Sampling dalam Analisis Isi}

Teknik sampling dalam analisis isi berprinsip sama dengan teknik sampling pada umumnya. Dapat menggunakan model sampling probabilitas (probability sampling), juga bisa menggunakan model sampling nonprobabilitas (nonprobability sampling). Ketika menggunakan model sampling probabilitas (probability sampling), keahlian statistik akan sangat diperlukan untuk menganalisanya, baik itu deskriptif ataupun inferensial. Dan jika menggunakan model sampling non-probabilitas (nonprobability sampling), perhitungan statistik dapat dikesampingkan. Penarikan sampel bisa diperdalam dengan mengambil sub-sample berkesesuaian dengan satuan analisis yang ditentukan. Penentuan ini bisa dilakukan secara acak (random); acak sederhana, sampel stratifikasi atau sampel kelompok/clusters. ${ }^{18}$ Menurut Bulaeng dengan menggunakan probability sampling termasuk dalam syarat yang penting dalam analisis isi, dia menuliskan sebagai berikut:

...tiga syarat yang cukup penting dalam penelitian analisis isi. Pertama, analisis isi menghasilkan kesimpulan-kesimpulan tentang jenjang wacana yang dapat digeneralisasikan. Analisis isi menggunakan metode probability sampling untuk menghasilkan sampel wacana yang representatif yang

${ }^{18}$ Hamidi, Metode Penelitian dan Teori Komunikasi, (Malang: UPT Penerbitan Universitas Muhammadiyah Malang, 2007), hlm. 133-136 
mencerminkan karakteristik populasi induk yang sebenarnya. Kedua, analisis isi lebih dominan bersifat kuantitatif dimana si peneliti mengelompokkan karakteristik-karakteristik wacana ke dalam kategori, menentukan frekuensi masuknya karakteristikkarakteristik yang berhubungan dengan masalah yang diteliti ke dalam kategori, dan melakukan uji statistik untuk menentukan besarnya perbedaan atau hubungan antara data frekuensi. 19

\section{Kategori dalam Analisis Isi}

Kategori dalam analisis isi harus mampu menggambarkan tujuan penelitian dilakukan (mencukupi tujuan), independent and mutually exclusive. Contoh analisis isi lirik suatu lagu dapat dikatagorisasikan menjadi beberapa elemen misalnya:

( intro )

- Lirik song 1

- Lirik song 2

- Lirik reff A

( Melody 1 )

- Lirik song 3

- $\quad$ Lirik song 4

- Lirik reff A

( Melody 2)

- Lirik add

- Lirik reff B

${ }^{19}$ Rahmawati Haruna, "Proximity Dan Kandungan Sosioemosi Isi Pesan Electronic Mail (E-Mail) di Mailing List UNHASML: Studi Analisis Isi dan Survei Pendapat Anggota mailing list UNHAS ML", Tesis, (Makassar: Program Pascasarjana Universitas Hasanuddin, 2004). Hlm. 56 
( Ending )

Format kategori bukan suatu kondisi yang kaku, kategorisasi bisa saja disesuaikan sesuai dengan obyek yang diteliti, misalnya surat kabar yang kategorisasinya akan memuat tentang: berita Ibu Kota, berita ekonomi, politik, pendidikan, opini, iklan, olah raga, hiburan, dll.

\section{Unit Rekam}

Unit analisis merupakan satuan kecil yang menjadi perhatian peneliti dalam suatu obyek penelitian. Dalam penelitian analisis isi tidak mengenal unit rekam yang tunggal, tetapi terdapat beberapa. Holsti menuliskannya:

- Kata atau simbol tunggal

Adalah unit paling kecil, kata tunggal itu diskrit, batasannya jelas.

- Tema

Seperti tema gender, kemanusiaan, Marxian, kapitalis, agama, globalisasi, terorisme, dll. Satuan analisisnya bukan lagi dalam satu kata, batasannya lebih luas. Tema merujuk pada porsi suau dokumen.

- Karakter (seperti dalam novel, film, radio, lirik lagu, televisi, drama, lagu, dll)

Sistem kategori yang digunakan untuk karakter pada dokumen biasanya mencakup hal-hal seperti status sosial ekonomi, status etnis, dll.

- Kalimat atau paragraph

Mempunyai keuntungan terdapat batasan yang jelas, tapi mempunyai kelemahan mempunyai beberapa tema atau topik. 
- Item-item

Ketika dokumen perlu dikomparasikan,maka item bisa digunakan sebagai unit analisisnya. Item dapat berupa buku, film, program radio, atau artikel dan lain-lain. ${ }^{20}$

\section{Sistem Enumerasi}

Terdapat empat cara proses enumerasi yakni:

- Simple binary coding

Gunanya untuk menunjukkan ada atau tidaknya kategori dalam dokumen.

- Frequency

Gunanya untuk menunjukkan frekuensi kemunculan kategori pada dokumen.

- Jumlah ruang yang digunakan pada kategori

- Intensitas yang menunjukkan kategori itu terwakili.21

\section{Validitas dalam Analisis Isi}

Validitas dalam analisis isi memperkuat asumsisuatu penelitian yang menggunakan analisis isi. Misalnya untuk menelaah bias suatu statemen yang terdapat pada suatu dokumen yang sifatnya berasal dari sumber pertama atau primer. Kuatnya unsur subyektifitas penulis pertama pada lembar-lembar dokumen bisa mentabukan hasil penelitian. Banyak hal yang bisa mempengaruhi atau juga yang motivasinya, misalnya ketenaran, pembelaan, narsisme, materialis, dan lain sebabagainya. Berbagai cara dalam validitas adalah berikut ini:

- Productivity

\footnotetext{
${ }^{20}$ Pawit M. Yusup, loc. cit.

${ }^{21}$ Andre Yuris, loc. cit.
} 
Pengukuran produktivitas, penilaian suatu kajian yang menunjukkan indikator yang tepat berhubungan dengan variabel.

- Predictive Validity

Penilaian kemampuan pengukuran dengan peristiwa yang akan datang

- Construct Validity

Pengukuran kesesuaian teori dan konsep yang diterapkan dengan metode atau alat yang dipakai dalam penelitian yang dilakukan. ${ }^{22}$

Validitas menurut Wimmer dan Domminick (2000):

"face validity assumes that an instrumens adequately measures if the categories are rigidly and satisfactorily defined and if the procedures of the analysis have been adequately conducted" (validitas permukaan mengasumsikan bahwa sebuah instrumen cukup mengukur jika kategori-kategorinya terdefinisikan dengan baik dan memuaskan dan jika prosedur analisisnya telah dijalankan dengan memenuhi syarat). ${ }^{23}$

\section{Reliabilitas Analisis Isi}

Sama halnya mirip dengan metode observasi, yakni dengan membandingkan kesimpulan-kesimpulan suat dokumen atau hasil analisis isi dengan peneliti lain. Jika hasilnya menunjukkan relativitas kesamaan maka suatu dokumen terebut menunjukkan kesahihannya.

Reliabilitas adalah keterandalan metode dan alat-alat yang digunakan dalam suatu penelitian dalam menjelaskan data-data yang tersedia. Jenis-jenis reliabilitas:

\footnotetext{
${ }^{22} \mathrm{Ibid}$

${ }^{23}$ Aeconomic, loc. cit.
} 
- Intercoder and intracoder

Adalah pemberian kode dari dalam dan dari luar

- Pretest

Adalah pengukuran perbedaan nilai antara pemberi-pemberi nilai

- Reliability Category

Adalah ukuran kemampuan pengulangan data dalam beberapa kategori. ${ }^{24}$

\section{Kelebihan dan Kekurangan}

Kelebihan pokok dari Analis isi adalah bersifat unobtrusive, yakni peneliti yang tidak bisa mempengaruhi atau mengintervensi objek yang sedang diteliti, karena analisis ini memang didak memakai manusia sebagai obyek penelitian. Analisis ini juga berkecenderungan (dengan beberapa pengecualian) relatif menggunakan biaya yang lebih murah. Analisis ini juga merupakan alternatif ketika penelitian survey sulit atau bahkan tidak bisa dilakukan, misalnya karena tekanan pihak-pihak atau kondisi sosial politik tertentu. Analisis isi melihat langsung bentuk komunikasi melalui teks dan transkrip, dari sini dapat diketahui corak interaksi sosial, pemahaman historis dan kultural, juga pemahaman kompleks pemikiran dan penggunaan bahasa. ${ }^{25}$

Kekurangan analisis isi adalah susah menemukan sumber data yang memuat pesan yang sesuai dengan definisi operasional dan konseptual ${ }^{26}$ yang biasa tercerai-berai dan rekuensi dan intensitas muncul beragam. Analisis isi tidak bisa gunakan untuk menguji

\footnotetext{
${ }^{24}$ Anonim, "Konsep-Konsep Pokok Analisis Isi Komunikasi", dalam website http://pustaka.ut.ac.id/puslata/online.php ?menu $=$ bmpshort_detail2\&ID=384_modul_metode_penelitian_komunikasi_kode_skom4435

${ }^{25}$ Wisnu Martha Adipura, op. cit., hlm. 114-115

${ }^{26}$ Hamidi, op. cit., hlm. 141-142
} 
hubungan antar variabel, tidak bisa melihat sebab akibat, akan tapi hanya bisa menilai kecenderungan. Terakhir, analisis isi is extremely time consuming ketika meneliti teks yang berdimensi ruang dan waktu yang luas; reduktif bila teksnya kompleks; sering menyederhanakan penghitungan kata, bukan esensi; sering mengabaikan konteks saat teks diproduksi (padahal setting produksi bisa mempengaruhi keseluruhan teks). ${ }^{27}$ Analisis isi tidak bisa mengungkapkan makna yang sifatnya tersembunyi (latent) dan sulit menyelidiki bagaimana ia dikatakan (how). ${ }^{28}$

\section{Simpulan}

Analisis isi (kuantitatif) dalam ranah komunikasi merupakan metode yang dapat digunakan untuk mengetahui atau menjelaskan muatan yang terkandung dalam suatu media komunikasi yang bersifat tampak (manifest). Sifat penelitian adalah analisis isi itu mendalam terhadap muatan suatu informasi yang tertulis atau tercetak dalam suatu media komunikasi. Analisis isi mempunyai tujuan (khususnya) untuk pengujian hipotesis. Teknik sampling dalam analisi isi dapat menggunakan sampling model probabilitas, bisa juga bisa memakai sampling model non-probabilitas. Terdapat unit rekam yang tidak tunggal tapi lebih dari satu atau banyak.

Paling tidak terdapat tiga jenis penelitian komunikasi analisis isi, yakni: bersifat deskriptif; penelitian tentang pengaruh dua pesan yang dihasilkan dua sumber terhadap variabel perilaku; penelitian mengenai efek pesan. Tiga langkah strategis analisis isi adalah: menetapkan model penelitian, mencari data data primer, dan mencari

\footnotetext{
${ }^{27}$ Wisnu Martha Adipura, loc. cit.

${ }^{28}$ Andre Yuris, loc. cit.
} 
pengetahuan kontekstual (selain definisi operasional dan konseptual) agar penelitian yang dilakukan tidak berada di ruang hampa.

Tahapan langklah-langkah dalam penelitian analisis isi adalah: perumusan masalah dan hipotesisnya, sampling sumber-sumber data, pengkategorian, pendataan suatu sampel dokumen coding, membuat skala dan interpretasi/ penafsiran data yang diperoleh.

Reliabilitas dalam analisis isi adalah keterandalan alat ukur dan validitas adalah kesahihan pengukuran atau penilaian dalam penelitian komunikasi. Kebenaran hasil penelitian analisis isi menjadi tidak terbatahkan dengan sederetan data yang cukup, penghitungan yang benar dan semua persyaratan terpenuhi, karena didukung oleh pembuktiannya.

\section{Daftar Pustaka}

\section{Buku}

Adipura, Wisnu Marta. "Analisis Isi", dalam buku Metodologi Riset Komunikasi: Panduan untuk Melakukan Penelitian Komunikasi. suntingan Pitra Narendra. Yogyakarta: Balai Kajian dan Pengembangan Informasi Yogyakarta dan Pusat Kajian Media dan Budaya Populer Yogyakarta. 2008.

Hamidi. Metode Penelitian dan Teori Komunikasi. Malang: UPT Penerbitan Universitas Muhammadiyah Malang. 2007.

Haruna, Rahmawati. Proximity dan Kandungan Sosio-emosi Isi Pesan Electronic Mail (E-Mail) Di Mailing List Unhas-Ml: Studi Analisis Isi dan Survei Pendapat Anggota Mailing List UNHAS ML". Tesis. Makassar: Program Pascasarjana Universitas Hasanuddin. 2004.

Krippendorff, Klaus. Content Analysis: Introduction to Its Theory and Methodology. terjemahan Farid Wajidi. Jakarta: PT. Raja Grafindo Persada. 1993.

\section{Internet}

Anonim. "Konsep-Konsep Pokok Analisis Isi Komunikasi". dalam website http://pustaka.ut.ac.id/puslata/online.php?menu=bmpshort_det 
ail2\&ID=384_modul_metode_ penelitian_komunikasi_kode_skom4436.

Diposkan Aeconomic."Pornografi Dalam Komik" (Analisis Isi Pornografi Dalam Komik Jepang Berjudul Ranma 1/2 dan Love Hina)". dalam website http://one.indoskripsi.com/judul-skripsi/ilmukomunikasi/\%E2\%80\%9Cpornografi-dalam-komik\%E2\%80\%9Danalisis-isi-pornografi-dalam-komik-jepang-be.

Restaty, Niken. "Riset Periklanan". dalam website http://pksm.mercubuana.ac.id/new/elearning/modul-risetperiklanan-3 sks_niken_restaty/43018-9-792956142617.doc.

Saifullah. "Pengaruh Iklan Politik di Televisi Pada Pilpres 2009 Terhadap Perilaku Pemilih di Makassar". dalam website http://Dunia_komunikasi?/pengaruh-iklan-politik-di-televisipada.html.

Yuris, Andre . "Communication Science: Content Analysis (Analisis isi)". dalam website http://andreyuris.wordpress.com/2009/09/02/analisis-isicontent-analysis/\#more-320.

Yusup, Pawit M. "Analisis Isi". dalam website http://images.andamawara.multiply.Multiply content.com/ attachment/0/SaLkKwoKCDcAAF9z2TI1/analisis \%20isi.pdf?nmid=211490085. 